\title{
Zahidé Lupinacci Muzart
}

Universidade Federal de Santa Catarina

\section{A paixão das florestas ou as viagens de Mme. van Langendonck}

Resumo: Neste artigo, analiso o diário de viagem ao Brasil da belga Mme. van Langendonck. De pequena nobreza, teve excelente educação, o que se percebe na leitura de suas páginas, cheias de observações inteligentes sobre o País, as colônias, os emigrantes e o governo brasileiro. Foi poetisa e escritora com obras publicadas como Aubepines, poesia, editado em 1841 Heures poétiques, poesia, editado em 1846. Quando ficou viúva, em 1857, decide renunciar à vida confortável de seu país natal e emigra para o Brasil, aqui permanecendo por dois anos. Sua aventura nas florestas do Rio Grande do Sul originou uma narrativa muito viva e colorida que publicou na Bélgica em 1862, sob o título de Une colonie au Brésil.

Palavras-chave: literatura de viagem; literatura de autoria feminina; Mme. van Langendonck.

Copyright (c) 2008 by Revista Estudos Feministas.

' Sigrid WEIGEL, 1986, p. 71, tradução minha.
Um texto descoberto em um arquivo empoeirado não será bom e interessante só porque foi escrito por uma mulher. É bom e interessante porque nos permite chegar a novas conclusões sobre a tradição literária das mulheres, saber mais sobre como as mulheres se enfrentam, em uma forma literária, a sua situação atual, as expectativas vinculadas a seu papel como mulheres, seus temores, desejos e fantasias e as estratégias que adotam para expressarem-se publicamente, apesar de seu confinamento ao pessoal e ao privado.

Vitorianas, saias longas, chapéus desabados, mãos enluvadas, algumas ainda trazendo terços e bíblias, quem diria? Tais senhoras, madames ou ladies, enfrentaram oceanos bravios, densas e sombrias florestas, áridos desertos, estepes sem fim, em busca de algo que nem elas mesmas no fundo sabiam e que nós podemos chamar de liberdade, a busca do outro ou a paixão do desconhecido...

Quem são essas aventureiras do século XIX que se distinguem de suas enclausuradas irmãs?

Nobres ou plebéias, estudiosas ou curiosas, naturalistas, pintoras, preceptoras, todas foram mulheres corajosas 
${ }^{2}$ Mary Louise PRATT, 1999.

${ }^{3}$ Ernst CURTIUS, 1957.

${ }^{4}$ Nara ARAÚJO, 1997.

${ }^{5}$ Zahidé Lupinacci MUZART, 1994. e despertam ainda hoje nossa atenção. As mulheres que viajaram no século XIX percorreram o mundo todo em busca da liberdade e dos sonhos! Foram feministas? Não em palavras, certamente, mas talvez suas ações, seus projetos e suas obras pudessem classificá-las assim. São muito variáveis os objetivos de cada viajante segundo suas origens e sua época, mas se destaca um objetivo comum a todas: a busca do conhecimento, a busca de sensações, a busca do novo, em suma, a busca do outro, e mesmo que esse outro fosse visto com os mesmos olhos da partida, dificilmente as viajantes, ao voltarem ao local de origem, olharão o seu país e os seus conterrâneos da mesma maneira. Isso é muito detectável no final do diário da Baronesa de Langsdorff em sua opinião sobre a Princesa de Joinville -, como nos de Mme. van Langendonck ou Mme. Toussaint-Samson. Há uma progressão nítida na visão das viajantes desde sua chegada ao Brasil, olhando a tudo e a todos um pouco com o que Mary Pratt chama de "olhos imperiais", 2 com interrogações e perplexidade da mulher européia branca e culta. Porém, ao final de alguns relatos, ao final das viagens, há uma mudança com a relativa "adoção" do País e de seus habitantes. Já não é um olhar puramente europeu, mas miscigenado e simpático ao país visitado.

Lendo escritos de viajantes, homens ou mulheres, encontra-se um estilo de escrever típico do viajante: o uso intensivo da descrição baseada na observação e, a todo momento, as comparações com a pátria, configurando a imagem analisada por Ernst Curtius de que "nada é como lá em casa", ${ }^{3}$ entre outros vezos... Porém, apesar de seguirem o mesmo estilo e as regras do relato de viagens, entre homens e mulheres existem diferenças. Nas descrições de algumas viajantes, misturam-se o público e o privado; na descrição dos homens, há predominância do público, da aventura, mas dessas características não participam todos os diários, em alguns predomina o estilo típico dos viajantes que procuram a veracidade de um testemunho e as observações de cunho científico. Segundo análise da pesquisadora cubana Nara Araújo, ${ }^{4}$ nos textos dos homens, não há estratégias discursivas. Em geral, não se autodiminuem, não se desculpam, não se justificam, nem suplicam. Eles são exatos, verdadeiros, isto é, autoritários (de autoridade) e masculinos. Não precisam de estratégias, porque detêm a verdade. Já as mulheres, como veremos, vão um pouco pelo desvio, pelas desculpas por se aventurarem em terreno masculino, em terreno do público, elas que deveriam ficar no privado, isto é, caladas! Já em trabalho anterior, estudei as estratégias das escritoras para se imporem no mundo masculino. ${ }^{5}$ Nas viajantes, é um pouco parecido, embora não haja a mesma submissão das escritoras brasileiras do 
${ }^{6}$ Carmen Oliver de GELABERT, 1872 , p. 8.

7 Maria Helena Pereira Toledo MACHADO, 1999, p. 238.

${ }^{8}$ Miriam Lifchitz MOREIRA LEITE apud MACHADO, 1999, p. 238. século XIX, que, com fórmulas de humildade, pretendiam inserir-se no mundo editorial, dominado pelos homens. Nas viajantes, também aparece o tom da desculpa. Em algumas, como na espanhola Carmen Oliver de Gelabert, lêem-se desculpas por não ser letrada e por não ter tido uma educação completa como a dos homens.

Há muitas diferenças de tom, de graus de modéstia nesses prólogos das viajantes, dependendo da classe a que pertencem. Carmen de Gelabert se diz "mulher do povo";" a Baronesa de Langsdorff pertence à nobreza, é instruída e aprecia ler os jornais todos os dias; Madame Toussaint-Samson não é nobre, mas tem instrução, e é muito inteligente nas suas críticas ao mundo masculino, como as que faz em relação aos editores franceses.

A consideração dos escritos de viagem produzidos por mulheres sugere, como acentua Maria Helena Pereira Toledo Machado,

uma inserção, no panorama da literatura de viagem, do olhar feminino caracterizado por uma certa espontaneidade, uma atitude menos formalista e analítica. Ao se colocar às margens do saber tradicionalmente monopolizado pelos homens, seus maridos e companheiros, os quais a maioria acompanhava, essas escritoras se deram a liberdade de registrar suas opiniões pessoais, geralmente em cartas e diários, o que valoriza seus escritos como fonte primária de história social. ${ }^{7}$

É assim que os vê Miriam Lifchitz Moreira Leite, uma das primeiras estudiosas dessa literatura, como fonte primária da história social do Brasil. "As escritoras poderiam contribuir duplamente para a história das mulheres", segundo ela. Por um lado, ao descreverem as particularidades da sociedade local, as viajantes estariam escrevendo sobre assuntos aos quais os homens estariam mais afastados, mais indiferentes, pois se considerava o "olhar feminino mais centrado no casamento e na família, e portanto mais sensível aos aspectos 'invisíveis' ou informais da sociedade e ao papel nela desempenhado pelas mulheres". ${ }^{8}$ É importante, pois, ver quem fala nesses textos e o lugar de onde fala: a mulher que tradicionalmente não tinha voz ou que, se a tinha, falava das margens. $O$ discurso das viajantes é um discurso com muitas facetas a serem analisadas, pois há questões de classe e de nacionalidade a serem consideradas.

Madame Toussaint-Samson ilustra muito bem a recepção aos diários femininos. Morou alguns anos no Brasil e escreveu um interessante diário, Viagem de uma parisiense ao Brasil, publicado em 1883. Voltando à França, quis publicá-lo e aí começou sua peregrinação à procura de editor. Todos Ihe negarem, enfaticamente, a publicação. Os 
${ }^{9}$ Adèle TOUSSAINT-SAMSON, 2003, p. 46.

${ }^{10}$ TOUSSAINT-SAMSON, 2003, p. 48. editores não queriam ouvir falar em publicação de viajante mulher e recusavam o texto sem sequer lê-lo. Ela diz, no prefácio do livro, que depois de tanto tempo no Brasil já tinha esquecido os usos e os costumes de seu país natal. E, além disso, os editores queriam relatos de "tigres, serpentes, missionários devorados pelos selvagens". Quando respondeu que "não", que propunha só um estudo dos costumes, dos hábitos de um país no qual tinha morado durante 12 anos e que tudo o que contava era verdadeiro, que não inventava nada, o editor respondeu-lhe: "Tanto pior! Inútil então me deixar seu manuscrito. Publicamos recentemente uma novela cuja cena se passava no Brasil e que fez muito sucesso: onças, jaguares, jibóias e selvagens, não faltava nada. Era muito emocionante".

Outro editor, ao negar-Ihe igualmente a publicação, disse-lhe que seu estilo era gentil, amável. Ela concluiu então com ironia: "Eu era mulher, não se poderia me conceder mais, já era muita honra que ele me fazia [...]". ${ }^{10}$

As mulheres mostram uma consciência de gênero, quer na escritura de viagens, quer, também, em textos autobiográficos, poéticos ou de ficção.

Neste artigo, gostaria de comentar o diário de uma curiosa belga, Mme. van Langendonck, cujo nome completo era Marie Barbe Antoinette Rutgeerts van Langendonck.

Segundo informações de seu bisneto no Brasil, Dr. Tácito Remi de Macedo van Langendonck, Marie Barbe Antoinette Rutgeerts van Langendonck, filha de Carolus Rutgeerts e de Maria Philomène Josephine de Linée Rutgeerts, nasceu em Antuérpia (Bélgica) em 7 de outubro de 1798. Lá se casou em 1827 com Jean Remi Félicien Philippe van Langendonck, oficial do Régiment de Guide e diretor do Hospital Militar de Charleroi.

Maria Barbe van Langendonck teve uma excelente educação, o que se percebe ao longo da leitura nas páginas de seu livro, cheias de observações inteligentes sobre o País, as colônias, os emigrantes e o governo brasileiro. Foi poetisa e escritora, publicou Aubepines, poesia, em 1841 e Heures poétiques, poesia, em 1846. Ao ficar viúva, em 1857 , decide renunciar à vida confortável de seu país natal e emigra para o Brasil, aqui permanecendo por dois anos, findos os quais retorna à Europa. Saudosa, três anos depois, reúne-se mais uma vez aos filhos, já fixados na colônia Harmonia, nas florestas do Rio Grande do Sul. Sua aventura originou uma narrativa muito viva e colorida que publicou na Bélgica em 1862, sob o título Une colonie au Brésil. ${ }^{11} \mathrm{O}$ livro, entre nós, foi traduzido e editado em Campinas mais de 100 anos depois, em 1990. Teve duas reedições, uma, em 2002, pela Editora Mulheres, de Florianópolis, e outra, 
${ }^{12}$ Como conta o editor na apresentação da reedição do livro: "Ce livre, nous en avions découvert une version brésilienne à la Foire du Livre de Porto Alegre (Editoras Mulheres \& Edunisc) en 2005. De retour à Bruxelles, nous l'avons retrouvé - dans sa version originale - dans un état pitoyable à la Bibliothèque Royale de Belgique. C'est cette version que nous vous proposons" (Serge NOËL, 2008).

13 "Parce que la Belgique semble vouloir occulter éternellement cette période sombre : impôts scandaleux, misère des plus pauvres, etc. [...] Parce qu'il s'agit du regard d'une femme (et c'est assez rare d'avoir des récits historiques de femmes) même si bourgeoise. Parce que la région du Rio Grande do Sul est méconnue des Européens. Parce que suivant la description de Madame Van Langendonck, ce sont bien des boat-people remplis d'Allemands et de Belges très pauvres qui fuyaient l'Europe pour espérer une vie meilleure au Brésil et à qui l'Ełat Belge vendait des images paradisiaques.... une réalité connue encore aujourd'hui dans de nombreux pays" (NOËL, 2008, tradução minha). Disponível em: http://www.biliki.com/ index.php?biliki=une-colonie-aubresil. Acesso em: 18 out. 2008.

${ }^{14}$ A Sociedade Montravel, Silveira e Cia., fundada em 1855, assumiu o compromisso de introduzir na Província do Rio Grande do Sul 1.440 colonos, mediante um adiantamento de 15 mil réis por colono, conforme tivesse esse mais ou menos de 12 anos de idade, além de um empréstimo de 57 contos de réis. A colônia foi autorizada como empreendimento particular pelo governo imperial em 1855. em 2008, na Bélgica, que teve por base a versão original de 1883 , pela Editions Biliki, cujo editor conheceu o livro a partir da edição brasileira. ${ }^{12}$

Madame van Langendonck é, pois, uma ilustrada dama, já com livros de poesia publicados e com 60 anos. É a viajante que abandona, em 1857, sua culta Europa pelas selvagens matas do Rio Grande do Sul para aí construir uma nova vida. O resultado: uma narrativa que se traduz em uma bela aventura e contém até lances fantásticos. Numa época em que as mulheres se contentavam, ou eram obrigadas a isso, com a vida familiar e que as sexagenárias ficavam de preferência ao pé do fogo, costurando e bordando, a corajosa belga prefere tecer sua história e atirase para o Brasil em um navio de emigrantes. Além da coragem demonstrada, era também uma mulher muito inteligente e perspicaz, e suas conclusões a respeito do que viu e ouviu nessas paragens, suas idéias sobre a emigração, tornam essa narrativa bem singular.

Esse diário mostra a situação, na época, em alguns países europeus cuja miséria obrigava o povo a tentar a sorte na América. Segundo o editor belga, a republicação do livro Pourquoi avons-nous décidé de publier un tel livre? prende-se a razões variadas:

Porque a Bélgica parece querer ocultar eternamente este período sombrio: impostos escandalosos, miséria dos mais pobres, etc.; porque se trata do olhar de uma mulher (e é muito raro lerem-se relatos históricos de mulheres) mesmo tão burguesa; porque a região do Rio Grande do Sul é desconhecida dos Europeus; porque, segundo a descrição de Mme Van Langendonck, são boat-people repletos de alemães e de belgas muito pobres que fugiam da Europa, esperando uma vida melhor no Brasil, e a quem o Estado belga vendia imagens paradisíacas [...] um fato consabido, ainda hoje, em numerosos países. ${ }^{13}$

A ligação de Mme. van Langendonck com o Brasil se inicia com a emigração de seus dois filhos para trabalhar como colonos no Brasil. Na verdade, os filhos integraram um projeto de colonização, a colônia Harmonia, no rio Jacuí, ${ }^{14}$ proposto pelo belga conde de Montravel (Sociedade Montravel, Silveira e Cia.), que, mais tarde, teria malogrado.

A minudente narrativa de Mme. van Langendonck, que, além de incluir os percalços da viagem no navio de emigrantes que a trouxe, relata a sua experiência como colona, suas tentativas de estabelecer-se em uma região agrícola, o que subentende desmatamento, plantações de milho e feijão, em primeiro lugar, e enfrentamento de todos os perigos de uma região isolada e ainda selvagem. Porém, o motivo maior é expresso na primeira frase do seu livro: 
${ }^{15}$ LANGENDONCK, 2002, p. 25.

"Creio que quando me decidi a emigrar para o Brasil, as combinações de interesses materiais eram apenas pretexto para ceder à atração pelo desconhecido, pois eu pensava menos no que íamos fazer no Brasil do que naquilo que íamos ver". ${ }^{15}$

Marie Barbe vem para as florestas quase sem preconceitos. É uma mulher de pequena nobreza, procede de uma cidade européia e, no entanto, abre-se ao novo mundo, à vida precária de emigrante e estranhamente não estabelece muitas comparações com o que deixou na Europa como outras viajantes, cujos diários pude ler.

Segundo o que ela mesma conta, sempre sentiu uma espécie de paixão para conhecer as florestas americanas e vê a oportunidade de realizar esse sonho quando seus filhos se engajam no projeto do conde de Montravel e emigram para participar da criação da colônia no Rio Grande do Sul, às margens do rio Jacuí.

Quando publica seu livro, na Bélgica, inclui o subtítulo Relatos históricos, razão por que não seria demais afirmar que ela desejava participar do gênero sério, dominado pelos historiadores e naturalistas. Mme. van Langendonck, como os demais viajantes, intenciona que sua narrativa seja autêntica, até certo ponto impessoal, entretanto, com freqüência, resvala para relatos próprios de diário íntimo, para observações de cunho pessoal: seus gostos e suas idiossincrasias. Um bom exemplo é um fato que ocorreu a caminho da cabana dos filhos e que lhe dá a oportunidade de falar do seu afeto por cães. Encontrando um cão de origem desconhecida, conta ela: "malgrado as prudentes advertências de nosso guia, dirigi-me diretamente ao cão, que, sem desconfiança, se deixou abordar e acariciar com um prazer evidente. Seu olhar doce convidava-nos positivamente a segui-lo".

Sua descrição de Porto Alegre é diferente das descrições dos viajantes, que, em geral, decepcionam-se com a chegada às cidades brasileiras:

Porto Alegre é uma bela cidade, inteiramente nova, construída em um terreno acidentado, perto do confluente de quatro rios, que formam uma quase ilha. Aí, o ar é salubre, as ruas, direitas e bem pavimentadas. O alto comércio é reservado aos alemães e aos portugueses: estes representam os judeus da Europa. Entre eles, tudo o que produz um ganho qualquer é justificado por suas relações. Por conseguinte, todos enriquecem. Chegando de ordinário ao Brasil com uma mão atrás e outra adiante, eles começam por vender aguardente de cana (cachaça) aos negros, cujos roubos compram ou receptam. 
16 LANGENDONCK, 2002, p. 29.

17 LANGENDONCK 2002, p. 31.

${ }^{18}$ LANGENDONCK, 2002, p. 49.

${ }^{19}$ Octavio IANNI, 2000, p. 11. $[\ldots]$

A aristocracia é representada, em Porto Alegre, por verdadeiros índios, brasileiros puro-sangue. Povo um pouco indolente, porém dócil, benevolente e de uma boa-fé incontestável. Hospitaleiro com tato e delicadeza, ele se esmera em tornar seu país agradável aos estrangeiros, cujos sufrágios Ihe dão prazer. No entanto, não the aponte melhoras a introduzir em seu governo ou em suas administrações; ele the escutará sem acreditar em você e lhe responderá sorrindo: Paciência.

Os alemães que, pela perseverança e o trabalho adquiriram, no Brasil, um grande conforto ou fortuna, permanecem simples e dignos, muito unidos entre si e educam perfeitamente seus filhos. ${ }^{16}$

Após passar alguns dias recuperando as forças em Porto Alegre, Mme. van Langendonck parte para a colônia, tendo o conde de Montravel se esforçado inutilmente para demovê-la do intento:

O Sr. de Montravel tentava me fazer abandonar o projeto de ir desmatar as florestas virgens: foram palavras vãs. Desde a idade da razão, a expressão floresta virgem dera livre curso a minha imaginação e deixara em mim o desejo intenso de ver uma. $O$ dia que me trazia a realização inesperada deste sonho enfim brilhava, apenas algumas léguas me separavam deste objetivo para o qual minhas aspirações se transportaram por tanto tempo; os argumentos mais lógicos foram, portanto, inúteis, nada pôde abalar minha decisão. ${ }^{17}$

Enfim, seu sonho de conhecer as florestas intocadas da América do Sul se realiza e o deslumbramento permanece, apesar das enormes dificuldades, dos problemas com animais selvagens: cobras e tigres e macacos ladrões!

Enfim, vi-me em plena floresta virgem! As árvores, as enormes lianas, a vegetação inteira, os pássaros de esplêndida plumagem: tudo me era novo, tudo me maravilhava. Em meio a esta jovem, grande, bela e vigorosa natureza, o reconhecimento e o amor pelo Autor dessas maravilhas transbordavam-me a alma. ${ }^{18}$

Como tão bem escreveu Octavio lanni: "Toda viagem se destina a ultrapassar fronteiras, tanto as dissolvendo como recriando-as. Ao mesmo tempo que demarca diferenças, singularidades ou alteridades, demarca semelhanças, continuidades, ressonâncias". ${ }^{19}$

Como a maioria dos viajantes, igualmente, Mme. van Langendock aqui se depara com a escravidão, prática contra a qual reagira e até escrevera, na Europa, mas, no Brasil, ao conviver com essa cruel realidade, deixa 
${ }^{20}$ LANGENDONCK, 2002, p. 41.

transparecer os mesmos preconceitos dos escravocratas e demonstra idéias arraigadas de branca de classe média alta e muito religiosa. Suas observações acerca dos escravos negros baseiam-se no que viu do relacionamento entre crianças negras e brancas. E a educação recebida como mulher, com todas as amarras e preconceitos, traduz-se no que escreve a respeito:

Em suma, a escravidão, tal como a vi no Brasil, me pareceu menos funesta aos negros que prejudicial à raça branca.

Quaisquer que sejam as causas disso, o fato é que os maus instintos inerentes à natureza do negro deixam nele bem pouco espaço para os sentimentos de probidade, de pudor e de moral. No entanto, é entre essas criaturas que os brasileiros deixam seus filhos chegarem à idade da razão: essas crianças são educadas com os negrinhos e brincam com eles, que, para algumas coisas, nunca são crianças.

Que os negrófilos europeus não se indignem com as minhas livres apreciações. Mais do que qualquer um deles, indignei-me, de longe, contra a escravidão. Enderecei em prosa e em verso aos proprietários de escravos epístolas enternecedoras. Minha simpatia pelo povo negro era profunda, eu me compadecia deste, censurava os brancos, com confiança, e certamente não foi sem combate que renunciei a minhas convicções.

Mas depois vi de perto os negros, eu os vi dos dois sexos em diferentes condições e estou firmemente persuadida de que sua moralização, se não é impossível, exigiria vários séculos de esforços. ${ }^{20}$

Mme. van Langendonck manifesta intolerância racial e analisa as relações entre homens e mulheres negros da perspectiva de sua classe, não consegue vê-los de outra maneira. Por outro lado, não demonstra racismo em relação aos indígenas, tendo ficado muito amiga de família indígena vizinha, "nativos", a que se liga com afeto. Apresenta, ao mesmo tempo, alguma consciência ecológica, deplorando a queima de madeiras nobres e desconhecidas na Europa, ainda que avalie essa perda em termos financeiros e não em malefícios para o meio em que passou a viver. Faz, ainda, um interessante comentário que ajuda a elucidar uma das razões da degradação das matas ciliares. Nesses locais, as árvores nunca eram vistas como vegetação protetora das margens dos rios, mas como madeira fácil de obter, porque podiam escoar pelas águas do próprio rio que ajudavam a preservar.

Mesmo no Brasil, não se conhece, nas cidades, as diferentes qualidades de árvores das florestas virgens. 
${ }^{21}$ LANGENDONCK, 2002, p. 54.

22 LANGENDONCK, 2002, p. 57.
Que pena que seja absolutamente necessário destruir essas fontes de riqueza por causa das insuperáveis dificuldades de transporte. Certamente essa é uma das causas pelas quais seria lógico desmatar inicialmente todas as margens dos rios. ${ }^{21}$

Quanto à emigração de que participa, sua crítica tem outro destinatário: os agentes de colonização na Europa a quem censura o envio de gente não qualificada e, ainda por cima, oriunda das prisões da Bélgica ou da Alemanha:

Mas a Sociedade Montravel, intimada a cumprir as obrigações de seu contrato com o governo brasileiro, pedira colonos aos agentes de colonização na Europa. Estes the enviaram não a lia desta populaça, mas a espuma dessa lia.

A chegada do primeiro transporte composto inteiramente por alemães pouco nos ocupou. ForamIhes concedidas colônias bastante afastadas da nossa para nos preservar de qualquer contato com eles. Infelizmente, não foi assim da segunda vez. Ela nos trouxe alguns refugos, recrutados nas prisões e depósitos de mendicidade. ${ }^{22}$

Ler essa narrativa faz-nos mergulhar em tempos difíceis e vistos com um olhar crítico e isento de chauvinismos, como mostra o texto abaixo, pois ela comenta as qualidades e os defeitos não somente dos emigrantes do seu país como dos de outras nações:

Entre os colonos vindos da Alemanha, estavam ladrões, incendiários, assassinos. Quase todos os indivíduos que haviam pego de quatro a doze anos de detenção e que se tinha medo de encontrar nas florestas. No entanto, é justo dizer que a Alemanha não envia apenas bandidos para $\circ$ Brasil. Muitos alemães são infatigáveis trabalhadores a quem nada espanta, a quem pouca coisa desencoraja. Comem muito, mas não são gulosos. Conseqüentemente, a ordem e o trabalho dão inevitavelmente a estes um bem-estar que eles jamais tiveram em sua primeira pátria.

O mesmo não acontece com os holandeses. Sem coragem moral e sem forças físicas, eles dão colonos lamentáveis. A sorte de uma carga deles que chegou à colônia Montravel foi deplorável.

Os agentes da colonização na Holanda espalharam nos vilarejos brochuras endereçadas àqueles que desejavam enriquecer de maneira rápida e segura. Dizia-se que no Brasil cada riacho possuía um leito de diamantes e de pedras semipreciosas, que aí se encontrava 0 ouro por toda parte, que esses valores eram recolhidos a mancheias. Que aí a terra produzia sem cultura e que em poucos anos daí se poderia voltar cumulado de riquezas. 
${ }^{23}$ LANGENDONCK, 2002, p. 5758.

24 LANGENDONCK, 2002. Este poema tem seis estrofes, é traduzido por Paula Berinson e está publicado na contracapa da edição da Editora Mulheres.
Esta brilhante perspectiva seduziu um grande número de famílias camponesas. ${ }^{23}$

Mme. van Langendonck era uma pessoa de trato afável e não só se liga à família indígena, vizinha de suas terras, à qual sempre se refere em termos elogiosos, como, em Porto Alegre, também faz muitos amigos. Era uma pessoa de fácil convívio e que realmente procurava entender terra e povo com simpatia.

A viagem para Mme. van Langendonck trouxe-lhe a experiência do estranhamento. Depois de permanecer por dois anos no Rio Grande do Sul, volta para a Bélgica, mas, da mesma forma que outras viajantes, sofre o desenraizamento agora da terra estrangeira a que se apegou. $A$ saudade impõe-lhe a volta ao Brasil, desta vez em definitivo, como escreve em poema intitulado "O retorno", de que reproduzo apenas três estrofes:
O Retorno
Brasil, te revejo após três anos de ausência
No entanto te deixei para não mais voltar,
Mas a força de tua atração eu ignorava,
Pensei apenas uma lembrança de ti levar.
Mas debaixo deste outro céu, o céu de minha pátria, Tive frio: de teu horizonte de fogo senti saudades Da majestosa floresta a que nunca se esquece Quando ali se viveu somente sob o olhar de Deus. Salve, ó nova pátria de meus filhos,
Salve. Eu venho recuperar à sombra de tuas florestas Este lugar ignorado onde minha vida vai acabar Aonde eu irei, pela última vez, abençoá-los. $[1863]^{24}$

\section{Referências bibliográficas}

ARAÚJO, Nara. "Otra vez, viajeras al Caribe". In: . El alfiler y la mariposa. La Habana: Letras Cubanas, 1997. p. 17-37.

CURTIUS, Ernst. Literatura européia e Idade Média latina. Rio de Janeiro: Instituto Nacional do Livro, 1979.

GELABERT, Carmen Oliver de. Viaje poético a Petropolis. Rio de Janeiro: Imprenta del Apostol, 1872.

IANNI, Octavio. "A metáfora da viagem". In: . Enigmas da modernidade-mundo. Rio de Janeiro: Civilização Brasileira, 2000. p. 11-31.

LANGENDONCK, Madame van. Une colonie au Brésil: récits historiques, par Madame van Langendonck. Anvers: L. Gerrits, 1862. 
. UMa colônIa no Brasll. Tradução de Paula Berinson e introdução de Augusto Meyer. Florianópolis: Editora Mulheres, 2002.

LANGSDORFF, Baronesa Emile de. Diário da Baronesa E. de Langsdorff. Relatando sua viagem ao Brasil por ocasião do casamento de S.A.R. o Príncipe de Joinville, 18421843. Tradução de Patrícia Chittoni Ramos e Marco Antônio Toledo Neder e introdução de Miriam Lifchitz Moreira Leite. Florianópolis: Editora Mulheres, 1999.

MACHADO, Maria Helena Pereira Toledo. "A literatura de viagem como fonte da história social. Uma análise crítica". Revista Estudos Feministas, Florianópolis, v. 7, n. $1 / 2$, p. 238-240, 1999. Resenha de Livros de Viagem, de Miriam Lifchitz Moreira Leite.

MOREIRA LEITE, Miriam Lifchitz. Livros de viagem (1803-1900). Rio de Janeiro: UFRJ, 1997.

MUZART, Zahidé Lupinacci. "Artimanhas nas entrelinhas." In: FUNCK, Susana Bornéo. Trocando idéias sobre a mulher e a literatura. Florianópolis: EDEME, 1994. p. 263-269.

NOËL, Serge. "Une colonie au Brésil". Biliki, 2008. Disponível em: http://www.biliki.com/index.php?biliki=une-colonieau-bresil. Acesso em: 18 out. 2008.

PRATT, Mary Louise. Os olhos do império. Relatos de viagem e transculturação. Tradução de Jésio Hernani Bonfim Gutierre. Bauru/SP: Edusc, 1999.

TOUSSAINT-SAMSON, Adèle. Uma parisiense no Brasil.Tradução de Maria Lúcia Machado e prefácio de Maria Inês Turazzi. Rio de Janeiro: Capivara, 2003.

WEIGEL, Sigrid. "La mirada bizca: sobre la historia y la escritura de las mujeres". In: ECKER, Gisela (Ed.). Estética feminista. Barcelona: Içaria Editorial, 1986. p. 69-98.

[Recebido e aceito para publicação em outubro de 2008]

\section{The Forests Passion or Travels of Mme. van Langendonck}

Abstract: In this article, I analyze the Brazil travel diary written by Belgium writer Mme. van Langendonck. Being of small nobility, she had an excellent education, what can be noticed by reading their texts full of clever observations about the country, the colonies, the emigrants, and the Brazilian government. She was a poet and writer, and published works such as Aubepines, poetry, in 1841, and Heures poétiques, poetry, in 1846. When she became widow, in 1857, decides to renounce to the comfortable life in her country and immigrates to Brazil, staying here for two years. Her adventure in the forests of Rio Grande do Sul originated a very vivid and colorful narrative that was published in Belgium in 1862 under the title Une colonie au Brésil.

Key Words: Travel Literature; Female Literature; Mme. van Langendonck. 